Research Article

\title{
The Efficacy of Psycho-Spiritual Mental Health Education for Improving the Well-Being and Perceptions of School Climate for Students At- Risk for School Failure
}

\author{
Thomas M. Kelley $^{1(1)}$ \\ Wayne State University
}

\author{
Brooke Wheeldon-Reece $^{2}$ \\ The Spark Initiative
}

\author{
Eric G. Lambert ${ }^{3}$ \\ University of Nevada
}

\begin{abstract}
${ }^{1}$ Professor Emeritus, Criminology and Criminal Justice, Wayne State University, Detroit, MI 48202, 248-227-1757 (cell), 248-524-0146 (fax). E-mail: aa5216@wayne.edu

${ }^{2}$ MBA, The Spark Initiative, Inc., Brandon, FL 33511, 813-662-6920 (cell). E-mail:brooker@thesparkinitiative.com

3 Ph.D., Department of Criminal Justice, Ansari Business Building 601D, University of Nevada, Reno, NV 89557, 775.784.4701 (office telephone).E-mail: ericlambert@unr.edu
\end{abstract}

Corresponding author:

Thomas M. Kelley, Ph.D.

E-mail:

aa5216@wayne.edu

eISSN: 2458-9675

Received: 28.03.2021

Revision: 13.06.2021

Accepted: 03.06.2021

(C) Copyright 2021

by Author(s)

\begin{abstract}
This preliminary study investigates the efficacy of the SPARK Mentoring Program, a mental health education intervention grounded the psycho-spiritual Principles of Universal Mind, Consciousness, and Thought for improving the well-being and perceptions for school climate of students at-risk for school failure. Students at-risk for academic failure were assigned to a treatment group $(n=75)$, and a waitlist comparison group $(n=34)$. Pre-and post-intervention, participants in both groups completed the Warwick-Edinburgh Mental Well-Being Scale, the Acceptance component of the Difficulties in Emotional Regulation Scale, and the Social and Emotional Learning, High Expectations, Caring Adults, and Peer Climate components of the Alaska School Climate and Connectedness Survey. Compared to the control group, students receiving this intervention (thirteen 45-60-minute sessions during regular school hours) reported improved mental health evidenced by a significant increase in mental well-being, state of mind, and hope for the future, and improved perceptions of school climate evidenced by a significant increase in conflict resolution, valuing academic success, and relational trust with teachers, peers, and school community.

Keywords:

Mental health • School climate • Three Principles/Innate Health • Relational trust • Academic failure
\end{abstract}

Citation: Kelley, T.M., Wheeldon-Reece, B., \& Lambert, E.G. (2021). The efficacy of psycho-spiritual mental health education for improving the well-being and perceptions of school climate for students at-risk for school failure. Spiritual Psychology and Counseling, 6(2), 73-93. https://dx.doi.org/10.37898/spc.2021.6.2.137 


\section{The Efficacy of Psycho-Spiritual Mental Health Education for Improving the Well- Being and Perceptions of School Climate for Students At-Risk for School Failure}

Mental health and positive perceptions of school climate (or SC) are particularly important for students at-risk for school failure (Cohen, McCabe, Michelli, \& Pickeral, 2009). Regarding SC, considerable research (e.g., Berkowitz, Astor, Moore, \& Benbenishty, 2016) shows that students at risk for school failure (hereafter studentsat-risk) who report positive perceptions of their SC are less likely to be overcome by negative influences and risk factors that can impede academic success and promote drop-out and other problem behaviors. Several independent reviews of SC research (e.g., Clifford, Menon, Cohen \& Hornung, 2012; Haggerty, Elgin \& Woodley, 2011; Thapa, Cohen, Guffey \& D'Alessandro, 2013) conclude that positive perceptions of SC by students at-risk are associated with several beneficial outcomes including improved academic achievement and graduation rates, and decreased delinquency, drug use, truancy, and drop-out. Furthermore, students-at-risk who report positive perceptions of their SC have fewer discipline referrals (Luiselli, Putnam, Handler, \& Feinberg, 2005), fewer harassment events and bullying incidents (Attar-Schwartz, 2009), fewer suspensions and expulsions (Lee, Gregory, Cornell, \& Fan, 2011), less fighting and antisocial behavior (Eliot, Cornell, Gregory, \& Fan, 2011), higher attendance and graduation rates (Allensworth \& Easton, 2007), and heightened relational trust with school peers, school staff, and the school community (Adelmen \& Taylor, 2010). Berkowitz, Astor, Moore, and Benbenishty (2016) concluded that positive perceptions of SC by students at risk can reduce achievement gaps among students of different socioeconomic backgrounds and between students with stronger and weaker academic abilities.

Considerable research shows that perceptions of SC for students at-risk are tightly intertwined with their mental well-being (Maras, Weston, Blacksmith \& Brophy, 2015; Way, Reddy \& Rhodes, 2007). The consensus of this research is that students who report positive perceptions of their SC also report higher levels of mental wellbeing, self-efficacy, resilience, creativity, satisfaction, and hope for the future (Kasen, Cohen, Chen, Johnson \& Crawford, 2009; Liu, 2012; Lucarelli et. al., 2014; Walters, Cross, \& Shaw, 2010; Wang, Selman, Dishion, \& Stormshak, 2010; White, La Salle, Ashby \& Meyers, 2014). Furthermore, positive views of SC by students-at-risk are consistently associated with lower levels of mental stress, depression, and anxiety (White, La Salle, Ashby \& Meyers, 2014).

The robust positive relationship between SC perceptions and mental health for students at-risk is well-documented. However, the direction of this relationship remains unclear. The prevailing view appears to be that the mental health of students at-risk is affected by the climate at their schools. This view has spawned a plethora of packages, programs, therapies, and techniques designed to "build" or construct more 
positive SC's from the "outside-in" (Kelley, Alexander, \& Pransky, 2017a; Marshall, 2005). On the other hand, Kohoulet, Dehghani, and Kohoulet (2015) stated, “... instead of students' mental health being affected by school climate, the situation may be reversed, such that students with poor mental health are more likely to have negative perceptions of their school climate" (p. 3). Put another way, students with good mental health may be more likely to have positive perceptions of their SC. This "inside-out" view suggests that if the mental health of students at-risk improves their perceptions of SC will become more positive. In the preliminary study that follows, we test this speculation by exposing students at-risk to mental health education grounded in the psycho-spiritual principles of Universal Mind, Consciousness, and Thought or The Three Principles/Innate Health (Kelley, 2008, 2011; Pransky \& Kelley, 2014; Kelley, Pettit, Pransky, \& Sedgeman, 2019).

\section{The Three Principles/Innate Health}

The Three Principles/Innate Health (or 3P/IH) is grounded in the work and insights of theosopher, Sydney Banks $(1998,2001,2005)$ who primary prevention pioneer, Donald Klein (1988), described as follows: “... this man, without any attempt on his part to do so, had suddenly entered into a vastly different level of awareness, a form of spontaneous spiritual transformation about which William James had written in the early 1900s..." (pp. 311-312). Banks asserted that a deeper understanding of people's psychological lives can be achieved by looking beyond the realm of form in which the social sciences generally restrict their scope of inquiry. Banks asserted there are spiritual Principles that create form and he used Universal Mind, Consciousness, and Thought as metaphors to represent these Principles. Banks posited that these three Principles are at the source of people's psychological life experiences. Banks asserted that these Principles are fundamental truths always present and operating in the psychological realm, much as gravity exists as a principle of the physical world and is always present. The Principles Universal Mind, Consciousness, and Thought have been described in depth elsewhere (for a review see Kelley, Pransky, \& Lambert, 2015; Pransky \& Kelley, 2014). A brief review follows.

\section{The Principle of Universal Mind}

Banks referred to Universal Mind as “... the intelligence of all things whether in form or formless... [and asserted that] Universal Mind holds the secret to all psychological functioning" (p. 59). Banks (1998) stated:

The Universal Mind, or the impersonal mind, is constant and unchangeable... The personal mind is in a perpetual state of change... Universal Mind and personal mind are not two minds thinking differently, but two ways of using the same mind... All humans have the ability to synchronize their personal mind with their impersonal mind to bring harmony into their lives. (p. 32) 
In sum, Banks viewed Universal Mind as formless energy that powers all life; an energy of which we are all a part; an intelligent life energy that powers the other two principles - Consciousness and Thought—which all people "use" to create their psychological lives. When we say "use" these three Principles, we are not mean that people must "do something"- that tools, techniques or new beliefs are necessary. Rather, we mean that everyone continually uses these Principles to create their psychological experiences in the same way everyone uses gravity to stay anchored to Earth.

\section{The Principle of Consciousness}

Banks saw Consciousness as the ability to be conscious, to take in life, to have experience, and to be aware of that experience. Banks (1998) referred to Consciousness as "the gift of awareness" (p. 39) ... [that] “... allows us to see creation” (p 47); "... that enables us to observe and experience the existence and the workings of the world we live in" (p.97). Banks (1998) stated, "Consciousness... allows for the recognition of form, form being the expression of Thought" (p. 39). In other words, Consciousness animates people's thinking via their physical senses forming their moment-to-moment psychological experiences.

Banks (1998) asserted further that "The gift of Consciousness combined with Mind and Thought allows us to experience life at an infinite number of levels of understanding" (p.75). Each level looks and feels very real at the time, but it is only "real" at that level of consciousness, and the level through which one sees the world can change at any moment with their next thought. The only experience people can have is their own thinking coming into their consciousness at that level and being experienced as "reality." Consciousness allows people to recognize that it is their use of the power of Thought, enlivened by the power of Consciousness, that creates their psychological lives and to view this process from a more impersonal or objective stance.

\section{The Principle of Thought}

Banks (1998) referred to Thought as “... the creative agent we use to direct us through life" (p.54) and he asserted that every person is born using the power of Thought to guide them through life. Thought stands between what happens out in the world and one's personal experience of what happens. Banks (2001) asserted, "Thought is not reality, but it is through thought that our realities are created" (ML, p. 49). Banks (1998) explained further, "Your thoughts are like an artist's brush. They create a personal picture of the reality you live in. It is we human beings that use Thought to produce such things as our feelings, moods and our overall perceptions of life" (p. 56).

Thus, Thought, as a Principle, refers to the fact that people have a power that allows them to create thoughts and to make meaning for themselves of their thoughts 
(i.e., people decide the importance of their thoughts via additional thoughts). Banks (1998) emphasized that Thought does not refer to what people think (i.e., thought content) or to the products of their thoughts (e.g., beliefs, perceptions, feelings, states of mind). Rather, is it "the fact that people think" that is a human common denominator. People's thoughts, enlivened by their consciousness, become their psychological experiences. People's behavior then unfolds in exact alignment with how the Principles of Universal Mind, Consciousness, and Thought make their lives appear to them (Kelley, Pettit, Pransky, \& Sedgeman, 2019; Kelley, Pransky, \& Lambert, 2015a). Banks (1998) stated:

There is nothing in the world that can come to pass without Thought and Consciousness... there would be no reality without Consciousness and Thought... Consciousness gives our five senses the ability to react to life: our seeing, our smelling, our touching...This is what brings it all] to life. But it can't come in by itself. It has to have a thought... Our thoughts in turn create our character, our behavior, and the behavior of all humanity. (p. 43)

\section{Innate Mental Health}

Banks (1998) further asserted that mental health is people's most natural state and is readily available to anyone whenever the personal mind quiets. In other words, when the personal mind quiets, the default setting of mental health engages. This mental health includes a non-self-conscious state of mind, unconditional feelings of selfesteem, an absence of insecurity, a capacity for insight and creativity, an unforced enjoyment of learning and natural curiosity (i.e., learning without "thinking about" learning), and an interest in others and in exploration of the world (Mills-Naim \& Mills, 2014). According to Banks, regardless of their current circumstances, mental status, and prior socialization, everyone has the same built-in predisposition for mental health and will exhibit this health whenever the personal mind quiets from maladaptive personal thought (e.g., worry, rumination, over-analyzing). Finally, Banks asserted that people's feelings are a barometer of the quality of their thinking, and mental well-being in the moment; reliably informing them whether they are operating from their innate health or overriding it with their own disordered personal thinking.

\section{Mental Health Education}

Banks asserted that when people have sufficient insight regarding the way the Principles of Universal Mind, Consciousness and Thought manifest within everyone to create their psychological lives, their mental health will improve. According to Banks, sufficient insight regarding the nature of these Principles is the only intervention necessary-no skills, no techniques, no new beliefs-only sufficient insight regarding the operation of these Principles, particularly the Principle of Thought. Even when techniques (e.g., meditation) are used, the change always comes from within via a quiet mind and healthy feelings such as well-being, gratitude, and 
hope that naturally unfold. As such, 3P/IH mental health education is not about helping people change their thoughts; it is about helping people realize that when their thoughts change, their feelings, perceptions, and state of mind also change. Nor is this education meant to help people find techniques or strategies to quiet the mind; it is about helping people realize that when the personal mind quiets, mental wellbeing and more positive perceptions of their existing circumstances surface.

The authors have observed that students at-risk do not often realize the distinction between what is happening in the outside world and their personal experience of it, or the meaning they make of it via their own personal thinking. These students do not typically recognize that their own thinking is the source of their psychological experiences. Rather, these students often confuse the source of their psychological experiences with what is happening "out there"-within outside reality. A student's anger is coming from a fellow student, a teacher, a parent. The very next day, however, the same student might respond differently to the very same people, because his/her thoughts have changed (Mills-Naim \& Mills, 2014).

We posit that students at risk can be assisted to recognize, in the moment, that what they experience is their own thinking made to appear real via their consciousness. If these students do not realize this fact, they will typically take their unhealthy personal thoughts to heart and often act on whatever "reality" these thoughts manifest. On the other hand, if these students realize what they are doing, they will be less likely to view the effects of these thoughts as "the truth" or the way things really are.

We have also observed that students at-risk do not often realize the resource of innate mental health available to them via a quiet mind. Thus, these students tend to chronically obscure this health via innocently misusing of the power of Thought (Kelley, Pettit, Pransky, \& Sedgeman, 2019; Kelley, Pettit, Sedgeman, \& Pransky, 2020). However, these students can be assisted to notice what they experience when their personal minds quiet down. They can be assisted to recognize that mental wellbeing and common sense are always available to them and that only their disordered personal thoughts - taken to heart - can obscure this innate health. Finally, students at-risk do not often realize they have an internal gauge that will reliably inform them when their personal thinking is disordered - their feelings (Kelley, Pransky, \& Lambert, 2016a). This means that using the signal of a negative or discomforting feeling these students can allow their personal minds to quiet and their innate wellbeing and common sense to surface.

\section{Supportive Research}

Considerable preliminary research exists in support the efficacy of 3P/IH mental health education for improving the mental health and behavior of a variety of 
client types. For example, Kelley, Mills, and Shuford (2005) reported that learning challenged students receiving $3 \mathrm{P} / \mathrm{IH}$ showed a significant improvement in reading level, self-esteem, and grade point average. Sedgeman and Sarwari (2006) reported that HIV-positive patients receiving $3 \mathrm{P} / \mathrm{IH}$ showed a significant reduction in stress and anxiety which was sustained at follow-up. Bannergee, Howard, and Mansheim (2010) reported that women in residential substance abuse treatment receiving $3 \mathrm{P} / \mathrm{IH}$ showed significant positive outcomes regarding substance use, criminal justice involvement, employment, housing, adverse effects of substance use, and psychological wellbeing. Halcón, Robertson, and Monsen (2010) reported that Somali and Ethiopian women refugees receiving $3 \mathrm{P} / \mathrm{IH}$ showed a significant decrease in posttraumatic stress symptoms. Kelley (2011) reported that adult prisoners on probation receiving 3P/ IH showed a significant improvement in mental well-being and mindfulness. Kelley, Pransky, and Lambert (2015a) reported that adults exposed to 3P/IH showed a significant improvement in nonattachment and regulating negative emotions, and a significant reduction in rumination, depression, and anxiety. Kelley, Pransky, and Lambert (2015b) reported that as adult's understanding of 3P/IH increased, their dependence on techniques (e.g., meditation) to experience mindfulness decreased, and their ability to maintain well-being during negative states of mind increased. Kelley, Pransky, and Lambert (2016a) reported that adults receiving 3P/IH showed a significant improvement in hedonic well-being, eudiamonic well-being, social wellbeing, and overall mental health. Kelley, Pransky, and Lambert (2016b) reported that adults exposed to $3 \mathrm{P} / \mathrm{IH}$ showed a significant improvement in mindful attention, mindful acceptance, flow, and flourishing mental health. Reece-Evans and Pevalin (2017) reported a significant increase in mental well-being for students and staff in a U.K. school receiving 3P/IH that was maintained at follow-up. Kelley, Alexander, and Pransky (2017a) reported that compared with a waitlist control group, children and adolescents receiving $3 \mathrm{P} / \mathrm{IH}$ showed a significant improvement in resilience, and participants at highest risk showed a significant decrease in risky behavior. Kelley, Hollows, Savard, and Pransky (2017) reported that compared with a control group, male residents in an English prison receiving 3P/IH showed a significant improvement in well-being, purpose in life, and prison behavior, and a significant decrease in anxiety and anger. Robertson, Halcon, and Hoffman (2018) examined the effects of culturally adapted $3 \mathrm{P} / \mathrm{IH}$ on coping and mental health outcomes for Somali refugee women post-resettlement and reported a significant decrease in depression as well as a significant improvement in several dimensions of coping. Kelley, Hollows, and Savard (2019) reported that compared to a control group, male prison residents receiving intensive $3 \mathrm{P} / \mathrm{IH}$ reported a significant increase in mental wellbeing and purpose in life, and a significant decrease in depression, anxiety, and anger which were either maintained or significantly improved at follow-up. El-Mokadem, DiMarko, Kelley and Duffield (2020) reported that compared with a waitlist control 
group, participants diagnosed with chronic fatigue syndrome receiving 3P/IH education reported a significant increase in psychological and physical well-being and a significant decrease in depression, anxiety, fatigue, and pain interference. The study that follows is the first to test the efficacy of SPARK 3P/IH-based mental health education for improving the mental health and perceptions of SC for students at-risk for school failure.

\section{The Present Study}

\section{Hypotheses}

Following exposure to SPARK mental health education, the authors predict that participants will report improved mental health. We used the following hypotheses to test this prediction:

Hypothesis 1: Compared with the control group, students receiving SPARK will show a significant increase in mental wellbeing.

Hypothesis 2: Compared with the control group, students receiving SPARK will show a significant improvement in state of mind.

Hypothesis 3: Compared with the control group, students receiving SPARK will show a significant increase in hope for the future.

We also predict that following exposure to SPARK, participants will report improved perceptions of SC. The Centers for Disease Control and Prevention (2009) and several prominent school climate researchers (e.g., Shetgiri et al., 2015) report that students' perceptions of school climate routinely show a positive relationship with "resolution of interpersonal conflict" and "value placed on academic success." Thus, we used the following hypotheses to test this prediction:

Hypothesis 4: Compared with the control group, students receiving SPARK will show a significant improvement in conflict resolution.

Hypothesis 5: Compared with the control group, students receiving SPARK will show a significant increase in valuing academic success.

Another consensus of school climate research is that students' perceptions of school climate consistently show a robust positive association with relational trust. (e.g., Dewit, Karioja, \& Shain, 2011; Krane, Karlson, Ness, \& Kim, 2016; McLaughlin \& Clark, 2010; Thapa, Cohen, Guffy, \& D'Alessandro 2013). In other words, on average, students with positive perceptions of school climate also report more warm, respectful, supportive connections with members of the school community (e.g., peers, teachers, parents). Thus, we used the following hypotheses 
to test this prediction:

Hypothesis 6: Compared with the control group, students receiving SPARK will show a significant increase in relational trust with teachers.

Hypothesis 7: Compared with the control group, students receiving SPARK will show a significant increase in relational trust with school peers.

Hypothesis 8: Compared with the control group, students receiving SPARK will show a significant increase in relational trust with the school community.

\section{Method}

\section{Participants}

This study was approved by an internal review board and informed consent to participate was obtained from all study participants and their caregivers. Five schools in lower income urban neighborhoods in Hillsborough County, Florida agreed to participate in the study. Administrators at each school informed their students and students' caregivers of the availability of the SPARK program and emphasized that participation was voluntary. 109 students agreed to participate. All participants were identified by their schools as at-risk for academic failure based on poor grades, overdue or incomplete homework assignments, truancy, and disruptive classroom behaviors (e.g., profanity, fighting). Participants' grade levels ranged from 8 through 12. Participants' ages ranged from 12 to 19 years. The mean age of the participants was 14.81 , with a standard deviation of 1.34. Sixty-eight percent reported as female and $32 \%$ as male. Approximately $86 \%$ reported as Black or Latinx, and $14 \%$ as White.

\section{Research Groups}

A treatment group was formed containing 75 students from three of the five participating schools. A waitlist control group was formed containing 34 students from the other two schools. For the treatment group, 64\% reported as female and $36 \%$ as male. For the control group, $79 \%$ reported as female and $21 \%$ as male. There was no significant difference between the groups on gender $\left(\chi^{2}=2.35\right.$, degrees of freedom, $2, \mathrm{p}=.31)$. For the treatment group, the age range was $12-19$ years, and the mean age was 14.67 , with a standard deviation of 1.35 . For the comparison group the age range was 13-18 years and the mean age was 15.25 , with a standard deviation of 1.26. Based on an independent t-test, there was no significant difference in age between the two groups. For the treatment group, $84 \%$ reported as Black or Latinx, and $16 \%$ reported as White. For the control group, 92\% reported as Black and Latinx, and $8 \%$ reported as White. There was no significant difference between the groups on race or ethnicity $\left(\chi^{2}=0.88\right.$, degrees of freedom, $2, \mathrm{p}=.35$ ). 


\section{Intervention}

The three Principles-based mental health education intervention is called SPARK - an acronym for "Speak to the Potential, Ability, and Resilience inside every Kid." SPARK was facilitated by two instructors each with several years of experience teaching this understanding to middle school and high school students. SPARK classes met weekly for 45-60 minutes during regular school hours for 13 consecutive weeks. Classes were held in regular classrooms at participating schools during regular school hours. Each SPARK class contained between 7 and 17 students. The average attendance of participants was $87 \%$, or approximately 11.5 of the 13 sessions. All 75 treatment participants completed a minimum of 7 SPARK classes.

The SPARK curriculum is comprised of the following core lessons: overview and introduction; principles behind your life and finding your SPARK; the power of Thought; your personal guide to decision making; community engagement; how state of mind influences judgment and reasoning; surviving mood swings; finding success in the midst of stress, feeling fear and insecurity without fear and insecurity; the inside-out nature of self-esteem; separate realities; cultivating meaningful relationships; dating and healthy relationships; mentoring and leading from the inside-out; bully prevention from the inside-out; academic success; college and career readiness; financial stability; parenting from the inside-out; creating the life designed for you; and graduation.

In the SPARK classes, stories, metaphors, symbols, videos, group activities, discussions, and games are used to introduce participants to the Principles of Universal Mind, Consciousness, and Thought and to help them grasp the way these Principles manifest within everyone. For example, the metaphor of the sun and clouds is used to represent how a student's innate mental health (i.e., the sun) can become obscured by her/his disordered personal thoughts (i.e., the clouds) and, like the sun, this health is always available whenever the personal mind quiets. Also, the metaphor of a tea bag being converted into tea by hot water is used to illustrate how thought is made to appear real via consciousness. SPARK instructors also assist students to recognize that mental health does not mean people feel good all the time; that people's feelings, perceptions, and states of mind change as their thinking changes. Students are further assisted to realize that the sensory manifestations of their thinking cannot damage or hurt them no matter how extreme, painful or insecure they feel, and that their innate well-being and common sense will resurface whenever the personal mind quiets.

\section{Measures}

Warwick-Edinburgh Mental Well-Being Scale-Short Form (WEMWBS-SF; Tennant et. al., 2007). The WEMWBS-SF comprises 7 items measuring mental well-being. The WEMWBS has good psychometric properties (Stewart-Brown et. al., 2009). Tennant and associates (2007) examined the relationship between the WEMWBS 
and other measures of mental well-being and mental ill-health and reported relatively high correlations with the other wellbeing measures (correlations $\geq 0.7$ ), and moderate negative correlations with the measures of mental ill-health. Responses are made on a 5 -point Likert scale ranging from 1 (none of the time) to 5 (all the time). A sample item is, "I have been feeling useful". Item responses are summed for a total WEMWBS-SF score.

Difficulties in Emotional Regulation Scale (DERS; Gratz \& Roemer, 2004). The DERS has 36-items that assess six components of emotional regulation. DERS subscale scores have been found to have high internal consistency within both clinical (e.g., Gratz et al., 2008), and non-clinical populations (Gratz \& Roemer, 2004). To measure "state of mind" we used the DERS-Non-Acceptance of Emotional Responses Scale which contains six items that measure people's ability to maintain well-being during unpleasant states of mind. A sample item is, "When I'm upset, I feel guilty for feeling that way." Items are measured on a 5 -point Likert scale $(1=$ almost never; to $5=$ almost always). Item responses are summed to obtain a total DERS-Acceptance score.

\section{Alaska School Climate and Connectedness Survey (ASCCS; American Institutes} for Research \& Association of Alaska School Boards, 2006). The ASCCS measures eight areas shown to have a strong relationship with SC. To measure "hope for the future" we used six items from the ASCCS Social and Emotional Learning component. A sample item is, "Setting goals for myself." To measure "conflict resolution" we used six additional items from the ASCCS Social and Emotional Learning component. A sample item is, "Respecting a classmate's opinions during a disagreement". To measure "valuing academic success" we used six items from the ASCCS High Expectations component. A sample item is, "I try hard to do well in school." To measure "relational trust with teachers" we used five items from the ASCCS Caring Adults component. A sample item is "My teachers treat me with respect." To measure "relational trust with peers" we used five items from the ASCCS Peer Climate component. A sample item is, "Students in this school help each other, even if they are not friends." To measure "relational trust with the school community" we used five items from the ASCCS Parent and Community Involvement component. A sample item is, "This school is a welcoming place for families like mine". Item responses are summed to obtain a total score for each ASCCS component.

Treatment participants completed the study's measures at pretest at the start of their first SPARK session and at posttest at the end of their final SPARK session. During comparable time periods, control participants completed the study's measures pre and post. During the duration of the study, all participants continued to participate in regular school classes and activities. 


\section{Results}

The descriptive statistics for the pre-test and post-test outcome measures of state of mind, mental wellbeing, hope for the future, conflict resolution, valuing academic success, and relational trust with teachers, peers, and school community are presented in Table 1. The distribution of the variables was checked, and statistical tests were conducted that showed that the variables had a normal distribution. In addition, the Cronbach's alpha values, a measure of internal reliability for the index outcome variables, were higher than .70 .

In Table 1, the mean and standard deviations for the outcome variables are presented for the entire group, the treatment group, and the control/comparison group. In addition, $t$-test values, using the independent $t$-test, are presented for the outcome variables to determine if there was a difference between the two groups on the pre-test and post-test for the outcome areas. Except for three outcome measures, there was no statistically significant difference $(\mathrm{p} \leq .05)$ between the treatment group and the control/comparison group on the pre-test results. However, for valuing academic success, connection with teachers, and connection with the school community, the treatment group was higher on the pre-test as compared with the control group. Regarding the post tests, for mental well-being, hope for the future,

Table 1.

Descriptive Statistics for Pre-Test and Post-Test Outcome Measures and Independent T-Test Results

\begin{tabular}{|c|c|c|c|c|c|c|c|}
\hline \multirow[t]{2}{*}{ Outcome } & \multicolumn{2}{|c|}{$\begin{array}{c}\text { All } \\
\text { Participants }\end{array}$} & \multicolumn{2}{|c|}{$\begin{array}{l}\text { Treatment } \\
\text { Group }\end{array}$} & \multicolumn{2}{|c|}{$\begin{array}{c}\text { Control/ } \\
\text { Comparison Group }\end{array}$} & \multirow[b]{2}{*}{$\begin{array}{l}\text { T-Test } \\
\text { Value }\end{array}$} \\
\hline & Mean & SDev & Mean & SDev & Mean & Sdev & \\
\hline Value Academic Success pre-test & 27.19 & 3.61 & 27.60 & 3.50 & 25.92 & 3.73 & $2.02 *$ \\
\hline Value Academic Success post-test & 27.10 & 3.45 & 27.89 & 2.55 & 24.62 & 4.61 & $3.31 * *$ \\
\hline Hope for the Future pre-test & 26.09 & 3.81 & 26.32 & 3.69 & 25.37 & 4.17 & 1.06 \\
\hline Hope for the Future post-test & 26.53 & 3.55 & 27.29 & 3.11 & 24.12 & 3.80 & $4.11 * *$ \\
\hline State of Mind pre-test & 17.11 & 3.33 & 17.21 & 3.65 & 16.79 & 2.13 & 0.70 \\
\hline State of Mind post-test & 17.57 & 3.47 & 17.89 & 3.57 & 16.54 & 2.99 & 1.68 \\
\hline Mental Wellbeing pre-test & 22.64 & 3.70 & 22.84 & 3.63 & 22.04 & 3.93 & 0.92 \\
\hline Mental Wellbeing post-test & 24.11 & 3.55 & 24.92 & 2.87 & 21.58 & 4.30 & $3.55^{* *}$ \\
\hline Conflict Resolution pre-test & 24.05 & 3.82 & 24.17 & 3.87 & 23.67 & 3.69 & 0.57 \\
\hline Conflict Resolution post-test & 24.67 & 3.61 & 25.55 & 2.89 & 21.92 & 4.26 & $3.90 * *$ \\
\hline Connect with Teachers pre-test & 19.72 & 3.24 & 20.23 & 3.23 & 18.12 & 2.75 & $2.87 * *$ \\
\hline Connect with Teachers post-test & 20.07 & 3.41 & 20.75 & 3.04 & 17.95 & 3.69 & $3.70 * *$ \\
\hline Connect with Community pre-test & 19.29 & 3.44 & 19.52 & 3.47 & 18.58 & 3.30 & 1.16 \\
\hline Connect with Community post-test & 19.64 & 3.28 & 20.20 & 3.08 & 17.92 & 3.33 & $3.09 * *$ \\
\hline Connect with Peers pre-test & 20.06 & 3.28 & 20.19 & 3.33 & 19.67 & 3.13 & 0.67 \\
\hline Connect with Peers post-test & 21.05 & 2.92 & 21.55 & 2.42 & 19.50 & 3.78 & $2.50 * *$ \\
\hline
\end{tabular}

Note. Sdev stands for standard deviation. The total number of the participants was 109 , with 75 in the treatment group and 34 in the control/comparison group. The Independent T-Test values are for the differences between the treatment group and the control comparison group. The Levene's Test of Equality of Variances was used and if statistically significant at $\mathrm{p} \leq .05$, the $\mathrm{t}$ value reported is the one for equal variances are not assumed.

$* \mathrm{p} \leq .05 \quad * * \mathrm{p} \leq .01$ 
valuing academic success, conflict resolution, and connection with peers, there were statistically significant differences between the two groups. Based on the t-tests, those in the treatment group scored statistically higher than those in the comparison group

Table 2.

Analysis of Covariance (ANCOVA) for the Outcome Variables Controlling for Pre-Test Scores, Gender, Age, and Race

\begin{tabular}{|c|c|c|c|c|}
\hline Outcome & Variables & Mean Square & F Value & Partial Eta-Squared \\
\hline \multirow[t]{5}{*}{ Value Academic Success } & Gender & 32.62 & $3.94 *$ & .04 \\
\hline & Age & 0.38 & 0.05 & .00 \\
\hline & Race & 7.81 & 0.94 & .01 \\
\hline & Pre-Test & 127.55 & $15.41 * *$ & .14 \\
\hline & Group & 124.90 & $15.08 * *$ & .14 \\
\hline \multirow[t]{5}{*}{ Hope for the Future } & Gender & 9.06 & 0.93 & .01 \\
\hline & Age & 5.77 & 0.59 & .01 \\
\hline & Race & 4.43 & 0.46 & .01 \\
\hline & Pre-Test & 117.00 & $12.04 * *$ & .12 \\
\hline & Group & 124.96 & $12.86^{* *}$ & .12 \\
\hline \multirow[t]{5}{*}{ State of Mind } & Gender & 0.51 & 0.05 & .00 \\
\hline & Age & 33.44 & 3.32 & .04 \\
\hline & Race & 9.18 & 0.91 & .01 \\
\hline & Pre-Test & 193.44 & $19.20 * *$ & .17 \\
\hline & Group & 47.35 & $4.70 *$ & .05 \\
\hline \multirow[t]{6}{*}{ Mental Wellbeing } & Gender & 16.87 & 1.69 & .02 \\
\hline & Age & 34.64 & 3.47 & .04 \\
\hline & Race & 2.16 & 0.22 & .00 \\
\hline & Pre-Test & 76.52 & $7.66^{* *}$ & .08 \\
\hline & Group & 127.15 & $12.74 * *$ & .12 \\
\hline & Gender & 2.25 & 0.24 & .00 \\
\hline \multirow[t]{4}{*}{ Conflict Resolution } & Age & 28.69 & 3.08 & .03 \\
\hline & Race & 3.12 & 0.34 & .00 \\
\hline & Pre-Test & 151.55 & $16.28 * *$ & .15 \\
\hline & Group & 144.10 & $15.47 * *$ & .14 \\
\hline \multirow[t]{5}{*}{ Connect with Teachers } & Gender & 5.94 & 0.64 & .01 \\
\hline & Age & 0.39 & 0.04 & .00 \\
\hline & Race & 18.24 & 1.98 & .02 \\
\hline & Pre-Test & 122.45 & $13.29 * *$ & .12 \\
\hline & Group & 47.94 & $5.20^{*}$ & .05 \\
\hline \multirow[t]{5}{*}{ Connect with Community } & Gender & 0.03 & 0.00 & .00 \\
\hline & Age & 5.73 & 0.65 & .01 \\
\hline & Race & 7.69 & 0.88 & .001 \\
\hline & Pre-Test & 131.10 & $14.94 * *$ & .14 \\
\hline & Group & 69.71 & $7.95 * *$ & .08 \\
\hline \multirow[t]{5}{*}{ Connect with Peers } & Gender & 10.99 & 1.51 & .02 \\
\hline & Age & 33.35 & $4.60 * *$ & .05 \\
\hline & Race & 0.32 & 0.04 & .00 \\
\hline & Pre-Test & 57.48 & $7.92 * *$ & .08 \\
\hline & Group & 42.28 & $5.83 * *$ & .06 \\
\hline
\end{tabular}

Note. The number of participants in the waitlist control group was 34 , and the number of participants in the experimental group was $75{ }^{*} \mathrm{p} \leq .05 * * \mathrm{p} \leq .01$ 
on the post-test for each of these the outcome areas. While treatment participants scored higher than comparison group on the post-test for state of mind, the difference between the two groups was not statistically significant at $p \leq .05$.

Analysis of covariance (ANCOVA) was used to determine if there were significant differences between the comparison group and treatment group on the eight posttest outcome measures while controlling for gender, age, race, and pre-test scores. These results are presented in Table 2. There were significant differences between the treatment group and comparison group on all eight post-test outcome measures even when controlling for gender, age, race, and pre-test scores. The treatment group was significantly higher on each post-test outcome measure as compared to the control group. Thus, it is concluded that each of the study's hypotheses is supported.

\section{Discussion}

The prevailing view of school climate researchers is that the mental health of students at-risk is substantially affected by the climate at their schools. The authors speculated that the situation may be the reverse - that, on average, if the mental wellbeing of these students improves their perceptions of their SC will also improve. This study tested this speculation by assessing the efficacy of SPARK 3P/IH-based mental health education for improving the mental well-being and perceptions of school climate for students at-risk for school failure. The results appear to support each of our hypotheses as follows:

\section{Mental Health}

Hypotheses 1, 2, and 3 were supported. Compared with the waitlist comparison group, students receiving SPARK reported improved mental health evidenced by a significant increase in mental wellbeing, state of mind, and hope for the future. These results were expected because, on average, when students realize the inextricable connection between their thinking and their experience, the way they relate to their maladaptive personal thinking and its discomforting effects begins to shift. They become less likely to believe and identify with the content or negative effects of this thinking (e.g., insecure feelings, distorted perceptions, low moods), and less inclined to view their unhealthy personal thoughts as "the truth," and to act on them. They begin to realize that these maladaptive personal thoughts have no power over them unless they think they do. They also realize they have "free will" to choose what thoughts to honor, entertain, and act on, and what thoughts to "take with a grain of salt" and allow to pass through.

Heightened hope for the future reported by these students is particularly noteworthy as considerable research shows a robust association between low hope for the future 
and school failure, addiction problems, and deviant behavior, and between high hope for the future and faith, love, health, and happiness, and less depression, anxiety, drug/alcohol use, boredom proneness, and fighting (Martin, McKinnen, Johnson, \& Rohsenow, 2011; Melton \& Schulenberg, 2007; Schulenberg, Hutzell, Nassif, \& Rogina, 2008; Shetgiri et al., 2015).

\section{Perceptions of School Climate}

Hypotheses 4 and 5 were also supported. Compared with the control group, students receiving SPARK showed improved perceptions of their school climate reflected by a significant increase in valuing academic success, and conflict resolution. These findings were expected because when students grasp sufficient understanding of how the power of Thought creates their (and everyone else's) psychological experiences from the "inside-out," the grip of their disordered personal thoughts begins to loosen and, in turn, they start to experience hope for the future and value in succeeding academically that were previously obscured by their conditioned personal thoughts. When students realize the connection between their thinking and their psychological experiences, they are less likely to relate to their thoughts, feelings, and perceptions as "the reality" or "the truth." Rather, they are more likely to "see" these experiences as "separate personal realities" created by their own thinking and made to appear real, in the moment, by their own consciousness. Thus, they are less likely to become gripped by these discomforting experiences, and to act on them. Also, they begin to take the biased judgments and negative behaviors of others less personally and see more sensible ways to avoid and resolve interpersonal conflicts (Shetgiri et al., 2015).

Hypotheses 6, 7 and 8 were also supported. Compared with the control group, students receiving SPARK showed improved perceptions of their SC evidenced by a significant increase in connection with teachers, peers, and the school community. These findings were expected because when students have sufficient understanding of how their psychological experiences are created, they realize that their (and everyone else's) feelings, perceptions, and states of mind are products of their own thoughts; not products of external circumstances, adverse life events, or how others treat them. In turn, their inclination to blame other people and external conditions for their psychological experiences lessens, and their ability to trust and form stronger affective bonds with others in the school community increases. These findings are noteworthy because considerable research (e.g., Byrk, Sebring, Allensworth, Luppescu, \& Easton, 2010; Comer, Haynes, Joyner, \& Ben-Avie, 1996; Malloy, 1998; Meier; 1995; Thapa, Cohen, \& D'Alessandro, 2013) shows that relational trust is routinely associated with positive perceptions of school climate. Sedgeman (2005) stated:

When people realize the one-to-one connection between thought and experience, they gain perspective on life. Changes in their experience of reality no longer look as though they were 
randomly caused by outside events or forces... Seeing the emergence of experience from thought appears to bring people peace of mind, no matter what they are thinking. Understanding Principles gives the power of experience to the person, not to life events. (p. 3)

\section{Implications for the School Community}

There is substantial evidence from several decades of research that mental wellbeing and positive perceptions of school climate are routinely associated with improved academic achievement and heightened social and emotional development of students, particularly students at-risk for school failure and other health damaging behaviors (e.g., drug use, delinquency). The authors posit, however, that absent sufficient recognition that thought is the formulator of people's every psychological experience, schools will continue to focus mainly on external strategies to improve their students' well-being and school climate perceptions. This "outside-in" approach may help quiet the minds of many students and temporarily release their innate wellbeing. In our view, however, "renting" improved well-being pales in comparison to "owning" this health via realizing how to allow the Principle of Thought to operate in one's own best interest (Kelley, Pransky \& Lambert, 2015b).

We have observed that when students (and other school community members) are exposed to mental health education grounded in the Principles of Mind, Consciousness, and Thought and, in turn, grasp sufficient understanding of the thought-experience connection, and the availability of innate well-being via a quiet mind, their mental well-being and school climate perceptions naturally improve. Students begin learning with more spontaneity and creativity via an enhanced capacity for insight. Students and teachers become more receptive to change and feel less compelled to defend their ingrained beliefs. Teachers take the unhealthy states of mind of their students less personally. Students' minds begin to relax, and the grip of their typical or habitual thinking begins to loosen so they are more open to new perspectives. Sedgeman (2005) stated, "Once people understand the thought-experience connection and realize how to re-access a healthy state of mind, they can sustain day-to-day peace of mind, wisdom, and well-being regardless of circumstances" (p. 47).

\section{Limitations}

This is a single exploratory study and additional research is needed to see if the findings can be replicated. Research among different students at-risk for school failure and at different schools in a wide array of regions should be undertaken to see if the results are consistent across different settings or are contextual and situational. Also, the number of participants studied could be larger, particularly for the comparison group. Furthermore, participants were not randomly assigned to experimental groups, and future studies should do so. Another limitation is that we did not conduct analyses to account for the nesting 
of participants within schools, and while participants' schools did not report any efforts to improve their school climate during the duration of the study, it is difficult to know if changes impacting school climate were made during that time. For example, teachers may have implemented additional reward systems or merely increased their implementation of existing strategies. Also, there may have been other school related events like school dances, parties, or perhaps negative events. Further research is also needed to determine the duration of the effects of SPARK. Many interventions have impressive short-term results, but null or inconsequential long-term results. It could be that follow-up education is needed to ensure that the self-reported positive changes are sustained. Finally, future studies should include other outcome factors, such as grades, drop-out rates, school rule violations, and other mental health measures (e.g., self-control).

\section{Conclusion}

This study evaluated the efficacy of SPARK 3P/IH-based mental health education for improving the mental health and the perceptions of school climate for students at-risk for school failure. The findings appear to support each of our hypotheses. Compared with the waitlist comparison group, students at-risk receiving SPARK reported improved mental health evidenced by a significant increase in mental well-being, state of mind, and hope for the future. Furthermore, compared with the control group, students atrisk receiving SPARK showed improved perceptions of SC evidenced by significant improvements in conflict resolution, valuing academic success, and relational trust with teachers, peers, and the school community. While more research is needed to test the efficacy of SPARK for improving the mental health and perceptions of SC for students at-risk for academic failure, these preliminary findings appear to warrant attention from education and mental health researchers and practitioners.

\section{References}

American Institutes for Research (2006). Alaska School Climate and Connectedness Survey. Fairbanks, AK: Association of Alaska School Boards.

Adelman, H., \& Taylor, L. (2010). Mental health in schools: Engaging learners, preventing problems, and improving schools. Thousand Oaks, CA: Corwin.

Allensworth, E. M., \& Easton, J. Q. (2007). What matters for staying on-track and graduating in Chicago public high schools: A close look at course grades, failures, and attendance in the freshman year. Research report. Chicago, IL: Consortium on Chicago School Research.

Attar-Schwartz, S. (2009). Peer sexual harassment victimization at school: The roles of student characteristics, cultural affiliation, and school factors. American Journal of Orthopsychiatry, 79(3), 407-420. DOI: 10.1016/j.chiabu.2008.12.010

Banerjee, K., Howard, M., Mansheim, K., \& Beattie, M. (2007). Comparison of health realization and 12-step treatment in women's residential substance abuse treatment programs. The American Journal of Drug and Alcohol Abuse, 33, 207-215. DOI: 10.1080/00952990601174758 
Banks, S. (1998). The missing link. Vancouver, BC: Lone Pine Publishing.

Banks, S. (2001). The enlightened gardener. Vancouver, BC: Lone Pine Publishing.

Banks, S. (2005). The enlightened gardener revisited. Vancouver, BC: Lone Pine Publishing.

Berkowitz, R., Astor, H., Moore, R., \& Benbenishty, R. (2016). A research synthesis of the associations between socioeconomic background, inequality, school climate, and academic achievement. Review of Educational Research, 87, 347-382. DOI: 10.3102/0034654316669821

Byrk, A. S., Sebring, P. B., Allensworth, E., Luppescu, S., \& Easton, J. 0. (2010). Organizing schools for improvement: Lessons from Chicago. Chicago, IL: The University of Chicago Press.

Clifford, M., Menon, R., Condon, C., \& Hornung (2012). Measuring school climate for gauging principal performance: A review of the validity and reliability of publicly accessible measures. Washington, DC: American Institutes for Research.

Cohen, J., McCabe, L., Michelli, N. M., \& Pickeral, T. (2009). School climate: Research, policy, practice, and teacher education. Teachers College Record, 111(1), 180-213.

Comer, J. P., Haynes, N. M., Joyner, E. T., \& Ben-Avie, M. (1996). Rallying the whole village: The Comer process for reforming education. New York: Teachers College Press.

DeWit, D. J., Karioja, K., Rye, B., \& Shain, M. (2011). Perceptions of declining classmate and teacher support following the transition to high school: Potential correlates of increasing student mental health difficulties. Psychology in the Schools, 48(6), 556-572.

Eliot, M., Cornell, D., Gregory, A., \& Fan, X (2011). Supportive school climate and student willingness to seek help for bullying and threats of violence. Journal of School Psychology, 48(6). 533-553. DOI: 10.1016/j.jsp.2010.07.001

El-Mokadem, J., DiMarko, K., Kelley, T. M., \& Duffield, L. (2020). Three Principles/Innate Health: The efficacy of a new psycho-spiritual mental health education intervention for people with chronic fatigue syndrome. Spirituality in Clinical Practice, Advance online publication. DOI: 10.1037/scp0000232

Grantz, K. L., \& Roemer, L. (2004). Multidimensional assessment of emotion regulation dysregulation: Development, factor structure, and initial validation of the Difficulties in Emotion Regulation Scale. Journal of Psychopathology and Behavioral Assessment, 26, 41-54. DOI: $10.1007 / \mathrm{s} 10862-008-9102-4$

Grantz, K. L., Tull, M. T., Baruch, D. E., Bornovalova, M. A., \& Lejuez, C. W. (2008). Factors associated with co-occurring borderline personality disorder among inner-city substance users: The roles of childhood maltreatment, negative affect intensity/reactivity, and emotion dysregulation. Comprehensive Psychiatry, 49, 603-615. DOI: 10.1016/j.beth.2010.11.003

Green, A. L., Ferrantee, S., Boaz, T. L., Kutush, K., \& Wheeldon Reece, B. (2021). Social and emotional learning during early adolescence: Effectiveness of a classroom-based SEL program for middle school students. Psychology in the Schools, 58(6), 1056-1069. DOI: 10.1002/pits.22487

Haggerty, K., Elgin, J. \& Woodley, A. (2010). Social emotional learning assessment measures for middle school youth. Social Development Research Group, University of Washington and the Raikes Foundation. DOI: 10.3102/0034654313483907

Halcon, L. L., Robertson, C. L., \& Monsen, K. A. (2010). Evaluating health realization for coping among refugee women. Journal of Loss and Trauma, 15, 408-425. DOI: 10.1080/15325024.2010.507645

Kelley, T. M. (2008). Principle-based correctional counseling: Teaching health versus treating illness. Applied Psychology in Criminal Justice. 4(2), 182-202. DOI: 10.1177/0306624X17735253 
Kelley, T. M. (2011). Thought recognition and psychological well-being: An empirical test of principle-based correctional counseling. Counseling and Psychotherapy Research. 11(2), 140147. DOI: $10.1080 / 14733145.2010 .485689$

Kelley, T. M., Alexander, J., \& Pransky, J. (2017). Drawing-out resilience in children and highrisk adolescents via exposing them to three psycho-spiritual principles. Journal of Child and Adolescent Behaviour, 5(2), DOI: 10.4172/2375-4494.1000343

Kelley, T. M., Hollows, J., Savard, D., Lambert, E. G., \& Pransky, J. (2017). Teaching health vs. treating illness: The efficacy of three principles correctional counseling with people in an English prison. International Journal of Offender Therapy and Comparative Criminology, 58(8), 661677. DOI: $10.1177 / 0306624 X 17735253$

Kelley, T. M., Hollows, J., \& Savard, D. (2019). The efficacy of intensive three principles correctional counseling for improving the mental health/resilience of people in an English prison. Journal of Offender Rehabilitation, 58(8), 561-577. DOI: 10.1177/0306624X17735253

Kelley, T. M., Mills, R. C., \& Shuford, R. (2005). A principle-based psychology of school violence prevention. Journal of School Violence, 4(2), 47-73. doi.org/10.1300/J202v04n02_04

Kelley, T. M., Pransky, J. \& Lambert, E. A. (2015a). Inside-out or outside-in: Understanding spiritual principles versus depending on techniques to realize improved mindfulness/mental health. Spirituality in Mental Health 17(3), 153-171. DOI: 10.1080/19349637.2014.998752

Kelley, T. M., Pransky, J., \& Lambert, E. (2015b). Realizing improved mental health through understanding three spiritual principles. Spirituality in Clinical Practice, 2(4), 267-281. doi. org/10.1037/scp0000077

Kelley, T. M., Pransky, J., \& Lambert, E. (2016a). Understanding spiritual principles, depending on techniques to realize and sustain optimal mental health. Spirituality in Mental 18(3), 217-238. DOI: $10.1037 / \mathrm{scp} 0000077$

Kelley, T. M., Pransky, J., \& Lambert E. (2016b). Realizing improved mindfulness/flow/mental health through understanding three spiritual principles. Journal of Spirituality in Mental Health. 19(2), 133-150. DOI: 10.1037/scp0000077

Kelley, T. M., Pettit, W. F., Pransky, J., \& Sedgeman, J. (2019). A new “inside-out” view of general factor p. European Psychiatry. 61, 85-87. DOI: 10.1016/j.eurpsy.2019.06.009

Kelley, T. M., Pettit, W. F., Sedgeman, J., \& Pransky, J. (2020) Psychiatry's pursuit of euthymia Another wild goose chase or an opportunity for principle-based facilitation? International Journal of Psychiatry in Clinical Practice, DOI: 10.1080/13651501.2020.1837182

Klein, D. C. (1988). The power of appreciation. American Journal of Community Psychology, 16, 305-324. DOI: 10.1007/BF00919373

Kohoulet, N., Dehghani, R. D., \& Kohoulet, N. (2015). Perceived school climate and students' mental health. International Journal of School Health, 2(4), 12-17. DOI: 10.1007/BF00919373

Krane, V., Karlsson, B. E., Ness, O., \& Hesook, S. K. (2016). Student relationship, student mental health, and dropout from upper secondary school: A literature review. Scandinavian Psychologist, 3(11), 1-25. DOI: 10.15714/scandpsychol.3.e11

Lee, T., Cornell, D., Gregory, D., \& Fan, X. (2011). High suspension schools and dropout rates for Black and White students. Education and Treatment of Children, 34(2), 167-192. DOI: 10.1037/a0030416

Liu, Y. Y. (2012). Students' perceptions of school climate and trait test anxiety. Psychological Reports, 111(3), 761-764. DOI: 10.1037/a0030416 
Lucarelli, J. F., Alaimo, K., Mang, E., Martin, C., Miles, R., Bailey, D., Kelleher, D. K., Nicholas B., Drzal, N. B., \& Liu, H. (2014). Facilitators to promoting health in schools: Is the key? Journal of School Health, 84, 133-140. DOI: 10.1111/josh.12123

Maras, M. A., Weston, K. J., Blacksmith, J. \& Brophy, C. (2015). Examining statewide capacity for school health and mental health promotion: A post hoc application of a district capacity-building framework. Health Promotion Practice. DOI: 10.1177/1524839914556091

Marshall, K. (2005). Resilience in our schools: Discovering mental health and hope from the inside-out. Minneapolis, MN: University of Minnesota, National Resilience Resource Center.

Martin, R. A., McKinnen, Johnson, J., \&, Rohsenow, D. J. (2011). Purpose in life predicts treatment outcome among adult cocaine abusers in treatment. Journal of Substance Abuse Treatment, 40, 183-188. DOI: $10.1016 /$ j.jsat.2010.10.002

McLaughlin, C., \& Clark, B. (2010). Relational matters: A review of the impact of school experience on mental health in early adolescence. Educational \& Child Psychology, 27, 91-103.

Meier, D. (1995). The power of their ideas: Lessons for America from a small school in Harlem. Boston: Beacon Press.

Melton, A. M. A., \& Schulenberg, S. E. (2007). On the relationship between meaning in life and boredom proneness: Examining a logotherapy postulate. Psychological Reports, 101, 10161022. DOI: $10.2466 / \mathrm{pr} 0.101 .4 .1016-1022$

Mills, R. C. (1995). Realizing mental health. NY: Sulzeurger \& Graham.

Mills-Naim, A. C., \& Mills, R. C. (2014). State of mind in the classroom: Consciousness and the essential curriculum for healthy learning. Brandon, FL: Center for Sustainable Change.

National School Climate Center (2016). School Climate. New York: NY.

Pransky, G. (1998). The renaissance of psychology. New York: Sulzburger \& Graham.

Pransky, J., \& Kelley, T.M.(2014). Three principles for realizing mental health:Anew psycho-spiritual view. Journal of Creativity in Mental Health, 9, 53-68. DOI: 10.1080/15401383.2013.875864

Reece-Evans, D. R., \& Pevelin, D. J. (2017). Using the principle-based model to improve wellbeing in school: A mixed-methods pilot study. Sage Open, DOI: 10.1177/2158244017716217

Robertson, C.L., Halcon, L., Hoffman, S.J. et al. (2018). Health realization community coping intervention for Somali refugee women. Journal of Immigrant Minority Health. DOI: 10.1007/ s10903-018-0804-8

Schulenberg, S. E., Hutzell, R. R., Nassif, C., \& Rogina, J. M. (2008). Logotherapy for clinical practice. Psychotherapy: Theory, Research, Practice, and Training, 45, 447-463. DOI: 10.1037/ a0014331

Sedgeman, J. (2005). Health realization/innate health: Can a quiet mind and a positive feeling. state be accessible over the lifespan without stress relief techniques? Medical Science Monitor, 11, 47-52. PMID: 16319796

Sedgeman, J. A., \& Sarwari, A. (2006). The effect of a health realization/innate health psychoeducational seminar on stress and anxiety in HIV-positive patients. Medical Science Monitor, 12(10), 397-399. PMID: 17006397

Shetgiri, R., Lee, S. C., Tillitski, J., Wilson, C., \& Flores, G. (2015). Why adolescents fight: A qualitative study of youth perspectives on fighting and its prevention. Academic Pediatrics, 15(1), 103-110. DOI: 10.1016/j.acap.2014.06.020 
Stewart-Brown, S., Tennant, A., Tennant, R., Platt, S., Parkinson, J., \& Weich, S. (2009). Internal construct validity of the Warwick-Edinburgh Mental Well-being Scale (WEMWBS): A Rasch analysis using data from the Scottish Health Education Population Survey. Health and Quality of Live Outcomes, 7:15, DOI: 10.1186/1477-7525-7-15

Tennant, R., Hiller, L., Fishwick, R., Platt, S., Joseph, S., Weich, S., Parkinson, J., Secker, J., \& Stewart-Brown, S. (2007). The Warwick-Edinburgh Mental Well-Being Scale (WEMWBS): Development and UK validation. Health and Quality of Life Outcomes, 5(1), 63. DOI: $10.1186 / 1477-7525-5-63$

Thapa, A., Cohen, J., Guffy, S., \& Higgens-D’Alessandro, A. (2013). A review of school climate research. Review of Educational Research, 83, 357-385. DOI: 10.3102/0034654313483907

Wang, M. T., Selman, R. L., Dishion, T. J., \& Stormshak, E. A. (2010). A Tobit regression analysis of the covariation between middle school students' perceived school climate and behavioral problems. Journal of Research on Adolescence, 20, 274-286. DOI: 10.1111/j.1532-7795.2010. 00648.x

Waters S., Cross D., \& Shaw, T. (2010). Does the nature of schools matter? An exploration of selected school ecology factors on adolescent perceptions of school connectedness. British Journal of Educational Psychology, 80, 381-402. DOI: 10.1348/000709909X484479

Way, N., Reddy, R., \& Rhodes, J. (2007). Students' perceptions of school climate during the middle school years: Associations with trajectories of psychological and behavioral adjustment. American Journal of Community Psychology, 40(3-4), 194-213. DOI: 10.1007/s10464-007-9143-y

White, N., La Salle, T., Ashby, J. S., \& Meyers, J. (2014). A brief measure of adolescent perceptions of school climate. School Psychology Quarterly, 29, 349-359. DOI: 10.1037/spq0000075 
